\title{
Tightening Polyelectrolyte Multilayers With Oligo Pendant Ions
}

\author{
Song Yi, William Leon, Dmitri Vezenov and Steven L. Regen* \\ Department of Chemistry, Lehigh University, Bethlehem, PA 18015
}

\section{Supporting Information}

\section{Table of Contents}

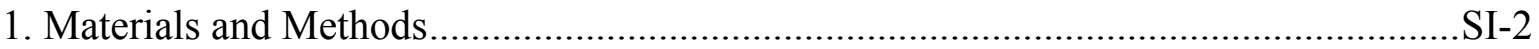

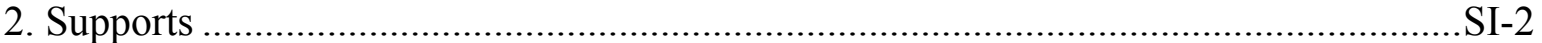

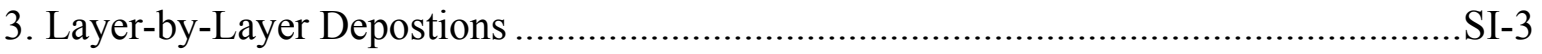

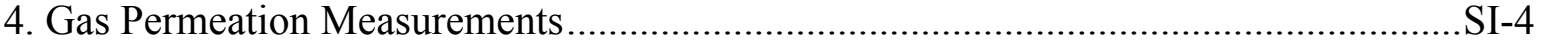

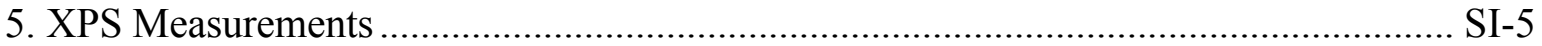

6. AFM Nanoindentation Experiments .................................................................... SI-6

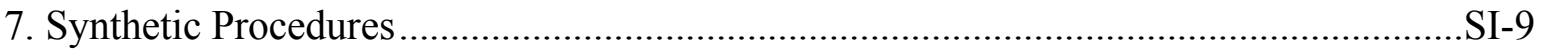

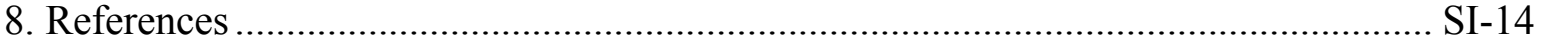


1. Materials and Methods. Branched poly(ethyleneimine) (PEI, Mw=70 kDa, Polysciences Inc., Warrington, PA), n-octadecyltrichlorosilane (OTS, Sigma-Aldrich Co., St. Louis, MO), poly(4-styrenesulfonic acid), sodium salt (PSS) (Mw=70 kDa , SigmaAldrich Co., St. Louis, MO), poly(4-vinyl benzyl chloride) (Mw=60 kDa, Polymer Source Inc., Dorval, Canada) and poly[1-(trimethylsilyl)-1-propyne] (PTMSP, Gelest, Inc., Morrisville, PA) were used as received. House-deionized water was purified using a Millipore Milli-Q-filtering system containing one carbon and two ion-exchange stages. Experimental methods that were used to quantify gas permeabilities and measure film thicknesses by ellipsometry were similar to those that have previously been described. ${ }^{1,2}$ Ellipsometry measurements were made using VASE ellipsometer (J.A. Woollam Co., Inc., Lincoln, NE), equipped with variable wavelength (from 250-1700 nm) and angle of incidence $\left(15^{\circ}-90^{\circ}\right)$ system, a $\lambda$ of $632.8 \mathrm{~nm}$ and an incidence angle of $70^{\circ}$ were chosen for measurements. The refractive indices that were used to estimate the thickness of the OTS and the polyelectrolyte multilayers were 1.46 and 1.41, respectively. All ${ }^{1} \mathrm{H}-\mathrm{NMR}$ spectra were recorded on a Bruker 500-MHz instrument; chemical shifts are reported in ppm and were referenced to residual solvents.

2. Supports. Supports that were made from PTMSP were prepared by using a casting technique. A typical casting apparatus consisted of a Pyrex glass square $(8$ in. $\times 8$ in $\times$ 1/8 in.), an aluminum centering ring seal, 160 ISO flange size (Kurt J. Lesker Co., Allentown, PA), and five (2.10 in. o.d. $\times 1.64$ in i.d. $\times 0.010$ in) low carbon steel washers (Boker's, Inc., Allentown, PA). The Pyrex glass square, ring seal, and five washers were cleaned with chloroform, methanol, and acetone, with the aid of kimwipes. The ring seal 
was then adhered to the glass square by using a 5\% toluene solution (HPLC grade) of PTMSP, which acted as "glue". The steel washers were placed symmetrically within the ring seal/glass square casting unit. A PTMSP/toluene casting solution (ca. $480 \mathrm{mg} / 30$ $\mathrm{mL}$ ) was then poured into the ring seal and covered with 15 large pieces of filter paper (Whatman qualitative circles, $18.5 \mathrm{~cm}$ ) in order to keep the casting unit dust-free, and also to avoid the solvent evaporating too fast. The toluene was allowed to evaporate for at least $15 \mathrm{~h}$, leaving a PTMSP film across the steel washers and glass square. A surgical blade (S/P Surgical Blades, Baxter Diagnostics) was used to cut out the individual washers. Water was poured into the ring seal to help separate the washers. The PTMSP cast films were placed between several large pieces of filter paper and allowed to dry for at least $24 \mathrm{~h}$. The resulting membranes, having a typical thickness of ca. $30 \mu \mathrm{m}$, were placed in antistatic bags for at least 15 min prior to use in composite membrane fabrication.

3. Layer-by-Layer Depositions. An OTS-modified silicon wafer (or PTMSP support), was further modified by depositing an adsorbed monolayer of $b$-PEI $(0.1 \mathrm{wt} \%$ with $0.1 \mathrm{M}$ $\mathrm{NaCl}$, at $\mathrm{pH} 10.0$ ) and washed with DI water, was subjected to layer-by-layer depositions. ${ }^{3}$ Typically, the substrate was immersed into $200 \mathrm{~mL}$ of an aqueous solution of polyanion (15 $\mathrm{mM}$ repeat unit, $0.1 \mathrm{M} \mathrm{NaCl}$ ) for $10 \mathrm{~min}$ without stirring, and then washed by immersing twice in $200 \mathrm{~mL}$ of deionized water for $5 \mathrm{~min}$ each without stirring, followed by air-drying in the clean room. To protect the membrane form dust, a cover was placed over the membrane with opening on the side. In the case of the PTMSP supports, LbL depositions were carried out using an automated Histo-Tek SL Slide Stainer (Sakura), equipped with glass inserts and $600 \mathrm{~mL}$ volumes of deionized water or $15 \mathrm{mM}$ aqueous 
solution of polycation or polyanion $(0.1 \mathrm{M} \mathrm{NaCl})$. All membranes were allowed to dry in the clean room for $48 \mathrm{~h}$ after the depositions were completed prior to gas permeation measurements.

4. Gas Permeation Measurements. Gas permeation measurements were made with a home-built stainless steel permeation apparatus. ${ }^{2}$ The gases studied were $\mathrm{H}_{2}$ (Ultra High Purity, water $<3$ ppm, Messer Griesheim Industries, Inc., Malvern, PA), $\mathrm{N}_{2}$ (prepurified grade, water $<3$ ppm, Airgas USA, LLC., Radnor, PA) and $\mathrm{CO}_{2}$ (Ultra Pure, water $<3$ ppm, Praxair, Inc., Danbury, CT). A membrane to be measured was placed in the permeation cell between two Viton rubber O-rings $(3.45 \mathrm{~cm}$ i.d., Scientific Instrument Services, Inc.) with a support screen (4.70 cm, Millipore Corp.) and held securely with a quick flange clamp (Scientific Instrument Services, Inc., not shown). Membranes were always placed in the cell such that the polyelectrolyte multilayers faced the high pressure side of the pressure gradient. The permeant gas travelled from the gas cylinder to an inline filter $(15 \mathrm{~m})$ and elastomer diaphragm regulator (Brooks Instrument, 8601D), which was connected to a Heise gauge port. Another plastic tubing line connected from the Heise gauge outlet to the permeation cell. The pressure gradient that was applied to each membrane was 40 psi. After passing through the membrane, the gaseous permeant was directed into a $40 \mathrm{~cm}$ long glass U-tube flowmeter (2 $\mathrm{mm}$ i.d.). The volumetric flow rate of the gas was then measured by recording the time $\left(t_{f}-t_{i}\right)$ that was required for a ethyl acetate plug $(\sim 0.5 \mathrm{~cm})$ to travel a set distance $\left(\mathrm{d}_{\mathrm{f}}-\mathrm{d}_{\mathrm{i}}\right)$, thereby sweeping out a defined volume. Measurements were taken until steady-state values were achieved (ca. $2 \mathrm{~h}$ for $\mathrm{H}_{2}$ or $\mathrm{CO}_{2}$ and ca. $4 \mathrm{~h}$ for $\mathrm{N}_{2}$ ). At least five volumetric flow rates were recorded for each membrane, and the mean and standard deviations were determined. The normalized flux 
was calculated with use of the mean volumetric flow rate, the area that was available for flow $\left(9.36 \mathrm{~cm}^{2}\right)$, and the pressure gradient (40 psi) that was employed. This procedure was repeated for the next permeant gas. In general, the permeation properties were first measured for $\mathrm{H}_{2}$, then for $\mathrm{N}_{2}$, and last for $\mathrm{CO}_{2}$.

Prior to gas permeation measurements, all membranes were allowed to dry in the laboratory ambient for $35 \mathrm{~h}$ after the layer-by-layer depositions were completed. During such time, the approximate temperature and relative humidity in the laboratory were $22 \pm$ $2^{\circ} \mathrm{C}$ and $40 \pm 10 \%$, respectively. To ensure that no damage to the membrane had occurred while these measurements were being made, after the last permeant was investigated (i.e., $\mathrm{CO}_{2}$ ), the $\mathrm{H}_{2}$ and $\mathrm{N}_{2}$ permeances were measured again and found to be unchanged.

5. XPS Measurements. X-ray photoelectron spectra were recorded using a SCIENTA ESCA-300 instrument (Scienta Omicron Uppsala, Sweden). The excitation radiation was a monochromatic $\mathrm{Al} K_{\alpha}$ x-ray beam $(1486.7 \mathrm{eV})$ generated by a $5 \mathrm{~kW}$ rotating anode source. Photoelectrons pass through an electrostatic electron lens into a $300 \mathrm{~mm}$ radius analyzer and are detected by a micro-channel plate coupled with a CCD camera. The base pressure in the vicinity of the sample is typically less than $1 \times 10^{-8}$ mbar.

High-resolution spectra were generally taken with an electron pass energy of $150 \mathrm{eV}$ within the analyzer. Energy resolution is on the order of $0.6 \mathrm{eV}$ under typical use conditions. Charge compensation for the analysis of non-conducting samples was accomplished by the use of a low energy electron flood gun. Spectra were processed and elemental composition was calculated using CASA XPS software. 


\section{AFM Nanoindentation Experiments}

\section{Nanoindentation Measurements.}

The PEM samples were prepared as described above. Films with thicknesses of 20-25 nm were formed on OTS modified Si wafer substrates. A single AFM probe (Vistaprobes FM from Nanoscience Instruments, Inc., Phoenix, AZ) was used throughout the whole series of AFM experiments to ensure identical probe parameters and to assist in unambiguous interpretation of the data and comparison of the mechanical properties of PEM films. The spring constant of the probe was determined from the thermal noise spectrum in air $(3.85 \mathrm{nN} / \mathrm{nm})^{4}$. The tip radius was acquired by fitting a circle to tip 1D profile (tip radius was $76.9 \pm 2.0 \mathrm{~nm}$ ) from tip shape standard imaging (NT-MDT TGT1, Moscow, Russia).

For each of the two samples, we used an MFP-3D AFM (Asylum Research, Santa Barbara, CA) to acquire force-volume maps (force-distance measurements in a twodimensional array - in $6 \times 6$ grid over a lateral space $8 \times 8 \mu \mathrm{m}$ across) at fixed maximum load. The maximum load applied to PEM films was varied between $90 \mathrm{nN}$ and $1290 \mathrm{nN}$ in $200 \mathrm{nN}$ intervals. To rule out contributions of plastic deformation to the force-distance data, only unloading part of the force-distance curve was analyzed. With the exception of very low maximum applied loads $(<300 \mathrm{nN})$, calculated values of Young's moduli were very similar for all maximum loads used (Figure SI-1). The force-volume maps were taken on a fresh area of the sample (10 $\mu \mathrm{m}$ apart) each time the maximum load was changed. To acquire representative statistics on the stiffness of the whole PEM sample, the force volume maps series (variable maximum load) was repeated at six different 
locations separated by approximately $2 \mathrm{~mm}$ in a $3 \times 2$ array.

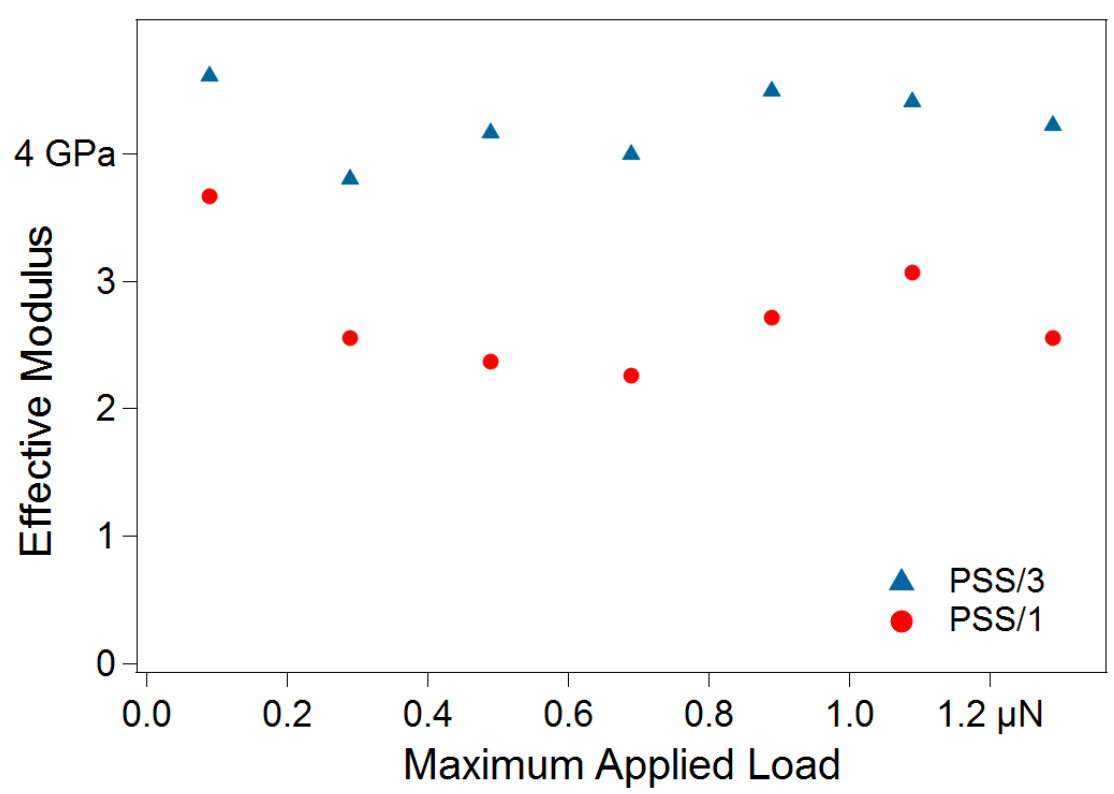

Figure SI-1: Dependence of effective moduli of $(\mathrm{PSS} / \mathbf{1})_{7.5}$ and $(\mathrm{PSS} / \mathbf{3})_{7.5}$ films on the maximum applied load. The values of Young's moduli were determined by fitting nanoindentation data to the JKR model at low indentations $\left(<2 \mathrm{~nm}\right.$ or $\left.F_{\max }=0 \mathrm{nN}\right)$.

\section{Calculation of Effective Young's Modulus from Nanoindentation Measurements.}

The effective Young's modulus of the PEM samples was determined by fitting forceindentation curves to a sphere-on-a-flat contact mechanics model (Figure 3 in main text). Depending on the relative magnitude of deformation due to surface forces and external load, two limiting cases can be used to describe the force-indentation relationship, corresponding to Jonson-Kendall-Roberts (JKR) or Derjaguin-Muller-Toporov (DMT) models. ${ }^{5}$ We found that both JKR and DMT models could describe force-indentation curves equally well, JKR model resulting in a higher (by up to 20\%) Young's modulus (Table SI-1). We used the results from the JKR model for comparison of the mechanical 
properties of these PEMs, since calculated Tabor elasticity parameter $\mu \approx 3.3$ is representative of the JKR conditions (DMT and JKR regimes are associated with $\mu<0.1$ and $\mu>5$, respectively). The choice of the model did not affect the conclusion that $(\mathrm{PSS} / \mathbf{3})_{7.5}$ PEM had 50 \% greater Young's modulus than $(\mathrm{PSS} / \mathbf{1})_{7.5}$.

The force-indentation response of an elastic material can be represented in a nondimensional form according to DMT and JKR models as shown in equations SI-1 and SI2:

$$
\begin{gathered}
\bar{\delta}=(1+\bar{P})^{\frac{2}{3}} \\
\bar{\delta}=\left(1+(1+\bar{P})^{\frac{1}{2}}\right)^{\frac{1}{3}}\left((1+\bar{P})^{\frac{1}{2}}-\frac{1}{3}\right)
\end{gathered}
$$

Here, the non-dimensional indentation $\bar{\delta}$ and non-dimensional applied load $\bar{P}$ are given by:

$$
\begin{gathered}
\bar{\delta}=\frac{\delta}{\delta^{*}} \quad \delta^{*}=\left(\frac{F_{a d h}}{K \sqrt{R}}\right)^{\frac{2}{3}} \\
\bar{P}=\frac{P}{F_{a d h}}
\end{gathered}
$$

where $R$ is the radius of curvature of the AFM probe, $K=\frac{4}{3} \frac{E}{1-v^{2}}$ is the elastic constant $(E$ is the Young's modulus and $v$ is the Poisson's ratio of the material), and $F_{a d h}$ is the adhesion force. For each indentation curve, we set $F_{a d h}$ and $\delta^{*}=\left(\frac{F_{a d h}}{K \sqrt{R}}\right)^{\frac{2}{3}}$ as fitting parameters leading to the determination of Young's modulus $E$ for known (fixed) values of $R$ and $v$ (set to 0.25 in our calculations). 
Table SI-1. Effective Young's moduli of PEM films indented at $1090 \mathrm{nN}$ max load. The results are obtained by fitting force-indentation data between $F_{a d h}$ and $F_{\text {max }}=0 \mathrm{nN}$ to JKR model (Equation SI-2, see Figure 3 in main text). Errors are $95 \%$ confidence limits for mean values averaged over 6 distant locations on the sample.

\begin{tabular}{|l|l|l|}
\hline PEM Composition & JKR Young's Modulus (GPa) & DMT Modulus (GPa) \\
\hline$(\mathrm{PSS} / \mathbf{3})_{7.5}$ & $4.49 \pm 0.37$ & $3.90 \pm 0.28$ \\
\hline$(\mathrm{PSS} / \mathbf{1})_{7.5}$ & $2.95 \pm 0.42$ & $2.57 \pm 0.36$ \\
\hline
\end{tabular}

\section{Synthetic Procedures}

Synthesis of Polymer 1. The synthesis of 1 was reported in our previous paper. ${ }^{6}$

Synthesis of Polymer 2. The synthesis of 2a is similar to the reported procedure. ${ }^{7}$

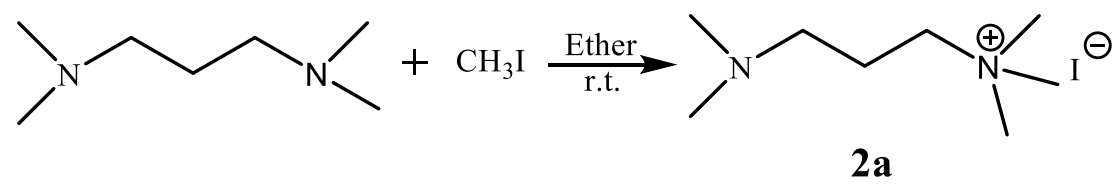

\section{Scheme SI-1}

A solution of N,N,N',N'-tetramethyl-1,3-diaminopropane $(5.0 \mathrm{~g}, 38.4 \mathrm{mmol})$ in $20 \mathrm{~mL}$ of diethyl ether was added iodomethane $(1.2 \mathrm{~mL}, 19.0 \mathrm{mmol})$, and the reaction mixture was stirred at rt. for $24 \mathrm{~h}$. The precipitate was collected and washed three times with diethyl ether to give the pure product $\mathbf{2 a}$ as a white powder $(4.9 \mathrm{~g}$, yield: $94.2 \%) .{ }^{1} \mathrm{H}$ NMR (500 MHz, D $2 \mathrm{O}): \delta 3.34(\mathrm{q}, 2 \mathrm{H}), 3.18(\mathrm{~s}, 9 \mathrm{H}), 2.44(\mathrm{t}, 2 \mathrm{H}), 2.24(\mathrm{~s}, 6 \mathrm{H}), 2.00(\mathrm{~m}$, $2 \mathrm{H})$.<smiles>CCCC(C)c1ccc(CCl)cc1</smiles><smiles>CCC(C)c1ccc(C[N+](C)(C)CCC[N+](C)(C)[O-])cc1</smiles> 


\section{Scheme SI-2}

A solution of poly(4-vinyl benzyl chloride) $\left(\mathrm{M}_{\mathrm{w}}: 60 \mathrm{kDa}, \mathrm{M}_{\mathrm{n}}: 23 \mathrm{kDa}, 300 \mathrm{mg}, 1.97\right.$ mmol repeat unit) in $20 \mathrm{~mL}$ of chloroform was mixed with $2.67 \mathrm{~g}(9.81 \mathrm{mmol})$ of compound 2a in $5 \mathrm{~mL}$ of methanol. The reaction mixture was stirred at $\mathrm{rt}$. overnight and then the solvent was evaporated in vacuo. The resulting residue was dissolved in $10 \mathrm{~mL}$ of water and dialysed against $2 \mathrm{~L}$ of a $\mathrm{NaCl}$ solution $(0.1 \mathrm{M})$ twice and then $2 \mathrm{~L}$ of deionized water three times (changing the dialysate every $12 \mathrm{~h}$ ) using a Float-A-Lyzer dialysis tube (MWCO 3.5 5 KD). After lyophilization, the final product 2 was obtained as a yellowish solid (560 mg, yield: $85.5 \%) .{ }^{1} \mathrm{H}$ NMR (500 MHz, $\left.\mathrm{D}_{2} \mathrm{O}\right): \delta$ 7.8-6.1 (brm, 4H), 4.54 (brs, 2H), 3.52 (brs, 4H), 3.24 (brs, 9H), 2.98 (brm, 6H), 2.52 (brs, 2H), 2.3-0.8 (brm, 3H). Anal. Calcd for $\mathrm{C}_{17} \mathrm{H}_{30} \mathrm{~N}_{2} \mathrm{Cl}_{2} \cdot 1.2 \mathrm{H}_{2} \mathrm{O}$ (repeat unit): C, 57.52: H, 9.20; N, 7.89. Found: C, 57.21; H, 9.54; N, 7.59.

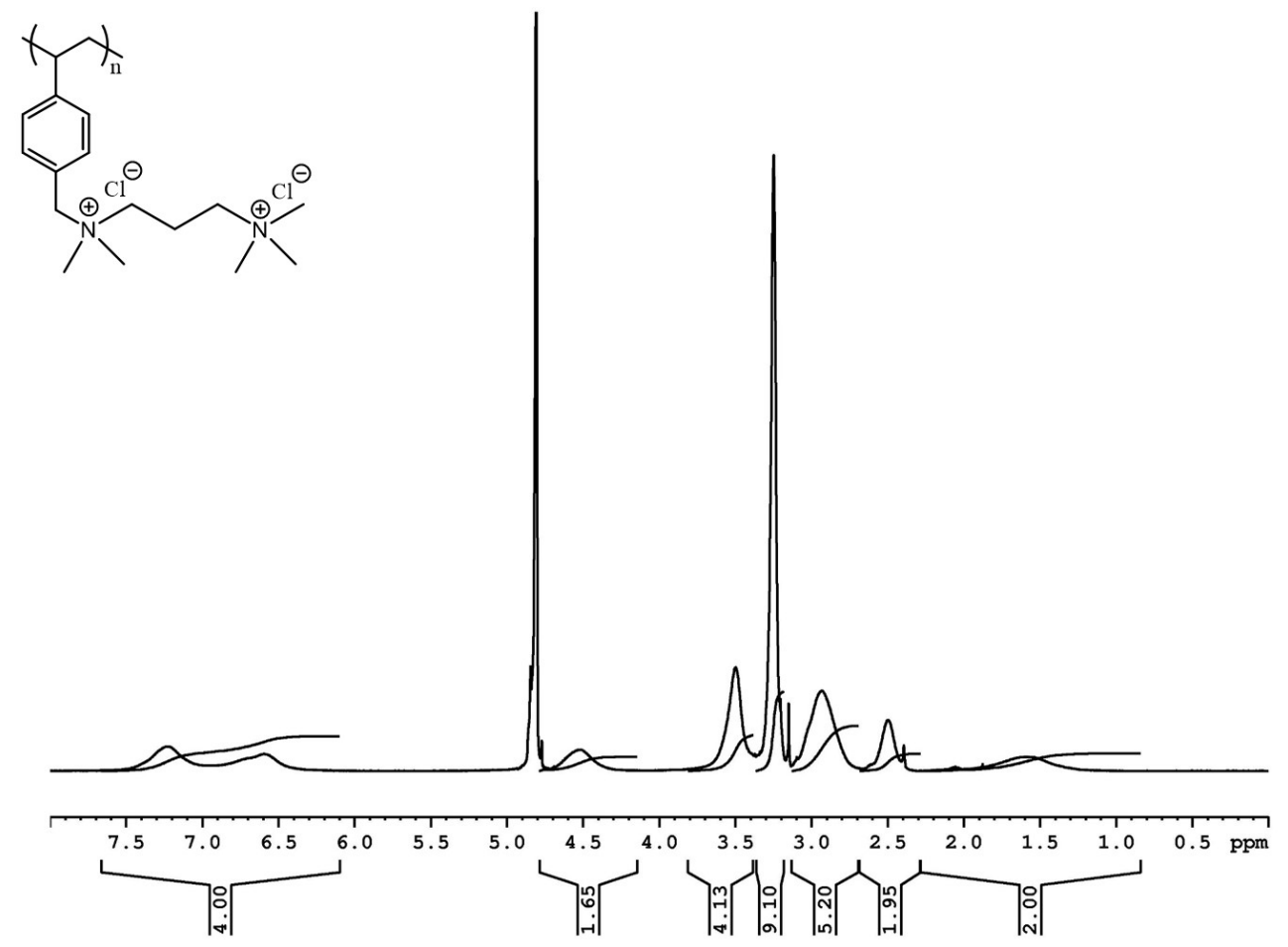


Figure SI-2: ${ }^{1} \mathrm{H}$ NMR spectrum of 2

Synthesis of Polymer 3. 3a was synthesized by following a literature procedure. ${ }^{8}$

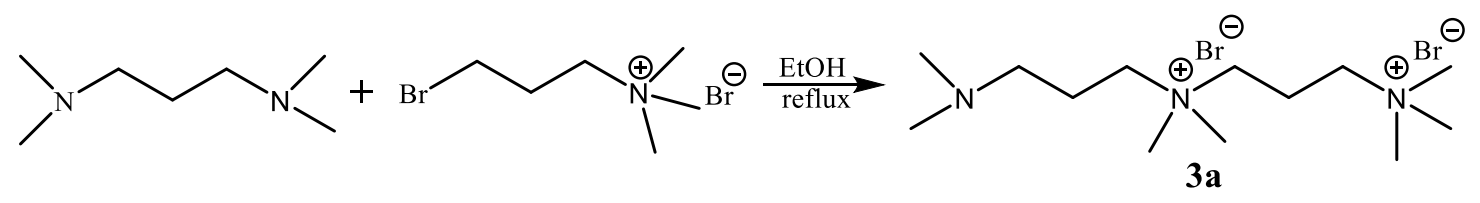

\section{Scheme SI-3}

To a solution of (3-bromopropyl)trimethylammonium bromide $(2.0 \mathrm{~g}, 7.66 \mathrm{mmol})$ in 30 $\mathrm{mL}$ of ethanol was added $6.2 \mathrm{~mL}$ of N,N,N',N'-tetramethyl-1,3-diaminopropane (5.0 g, $38.4 \mathrm{mmol}$ ), and the reaction was refluxed for $24 \mathrm{hrs}$. When the reaction was complete, diethyl ether was added to precipitate the polymer. After washing with $50 \mathrm{~mL}$ of diethyl ether (three times), the final product 3a was obtained as a white powder (2.6 g, yield: 86.7\%). ${ }^{1} \mathrm{H}$ NMR (500 MHz, $\mathrm{D}_{2} \mathrm{O}$ ): $\delta 3.43(\mathrm{~m}, 6 \mathrm{H}), 3.22(\mathrm{~s}, 9 \mathrm{H}), 3.16(\mathrm{~s}, 6 \mathrm{H}), 2.48(\mathrm{t}$, $2 \mathrm{H}), 2.36(\mathrm{~m}, 2 \mathrm{H}), 2.28(\mathrm{~s}, 6 \mathrm{H}), 2.02(\mathrm{~m}, 2 \mathrm{H})$.

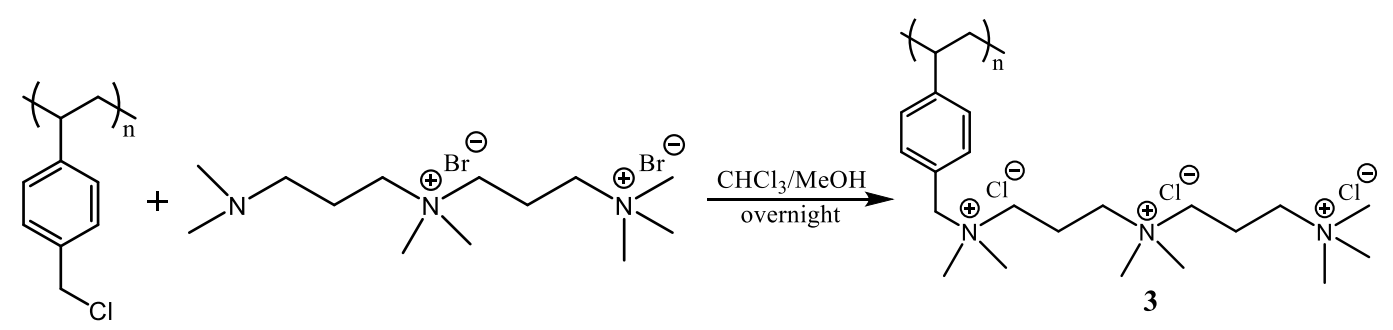

Scheme SI-4

A solution of poly(4-vinyl benzyl chloride) $\left(\mathrm{M}_{\mathrm{w}}: 60 \mathrm{kDa}, \mathrm{M}_{\mathrm{n}}: 23 \mathrm{kDa}, 330 \mathrm{mg}, 2.16\right.$ mmol repeat unit) in $20 \mathrm{~mL}$ of chloroform was mixed with compound 3a in $10 \mathrm{~mL}$ of methanol. The reaction mixture was stirred at $\mathrm{rt}$ overnight and then the solvent was removed under reduced pressure. The resulting residue was dissolved in water and dialysed against $2 \mathrm{~L}$ of $\mathrm{NaCl}$ solution $(0.1 \mathrm{M})$ twice and then $2 \mathrm{~L}$ of deionized water three times (changing the dialysate every $12 \mathrm{~h}$ ) using a Float-A-Lyzer dialysis tube (MWCO 3.5 5 KD). After lyophilization, the final product 3 was obtained as a yellowish solid 
(948 mg, yield: 96.4\%). ${ }^{1} \mathrm{H}$ NMR (500 MHz, $\mathrm{D}_{2} \mathrm{O}$ ): $\delta$ 7.78-6.18 (br, 4H), 4.72-4.28 (brs, 2H), 3.94-3.42 (br, 8H), 3.32-3.10 (m, 15H), 3.10-0.78 (m, 13H). Anal. Calcd for $\mathrm{C}_{22} \mathrm{H}_{42} \mathrm{~N}_{3} \mathrm{Cl}_{3} \cdot 2 \mathrm{H}_{2} \mathrm{O}$ (repeat unit): C, 53.83: H, 9.44; N, 8.56. Found: C, 54.11; H, 9.89; N, 8.02 .

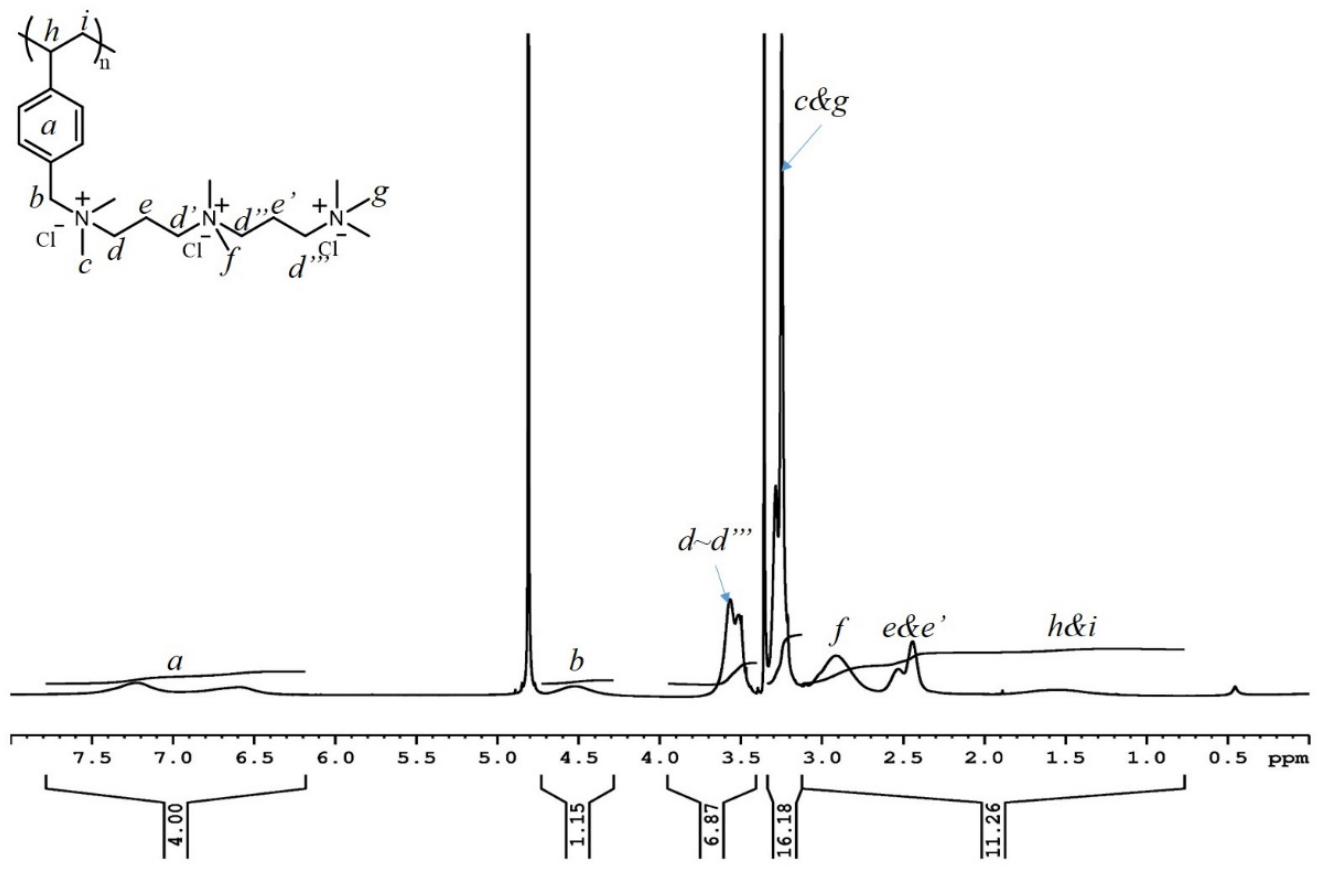

Figure SI-3: ${ }^{1} \mathrm{H}$ NMR spectrum of 3 
Table SI-2 Observed permeances and selectivities (at 40 psi) across PEMs ${ }^{a}$

\begin{tabular}{|c|c|c|c|c|c|c|c|}
\hline Membrane $^{\mathrm{b}}$ & $\begin{array}{l}\text { PEM } \\
(\mathrm{nm})\end{array}$ & $\begin{array}{c}\mathrm{H}_{2} \\
\text { (GPU) }\end{array}$ & $\begin{array}{c}\mathrm{CO}_{2} \\
(\mathrm{GPU})\end{array}$ & $\begin{array}{c}\mathrm{N}_{2} \\
\text { (GPU) }\end{array}$ & $\mathrm{H}_{2} / \mathrm{CO}_{2}$ & $\mathrm{CO}_{2} / \mathrm{N}_{2}$ & $\mathrm{H}_{2} / \mathrm{N}_{2}$ \\
\hline \multirow[t]{2}{*}{$\mathrm{P}^{\mathrm{c}}$} & ---- & 710 & 1800 & 310 & 0.39 & 5.8 & 2.29 \\
\hline & $\cdots$ & 690 & 1700 & 300 & 0.40 & 5.7 & 2.30 \\
\hline \multirow[t]{2}{*}{$\mathrm{P}-[\mathrm{PSS} / \mathrm{P} 1]_{7.5}$} & $20.6 \pm 0.2$ & 131 & 44.9 & 0.44 & 2.92 & 102 & 298 \\
\hline & & 124 & 48.7 & 0.48 & 2.48 & 101 & 258 \\
\hline \multirow[t]{2}{*}{$\mathrm{P}-[\mathrm{PSS} / \mathrm{P} 1]_{9.5}$} & $25.8 \pm 0.6$ & 106 & 36.4 & 0.36 & 2.91 & 101 & 294 \\
\hline & & 108 & 41.4 & 0.41 & 2.61 & 101 & 263 \\
\hline \multirow[t]{2}{*}{$\mathrm{P}-[\mathrm{PSS} / \mathrm{P} 2]_{6.5}$} & $22.5 \pm 0.6$ & 81.4 & 28.8 & 0.64 & 2.83 & 45 & 127 \\
\hline & & 72.8 & 28.2 & 0.55 & 2.58 & 51 & 132 \\
\hline \multirow[t]{2}{*}{$\mathrm{P}-[\mathrm{PSS} / \mathrm{P} 2]_{7.5}$} & $26.3 \pm 0.5$ & 62.9 & 17.2 & 0.24 & 3.66 & 72 & 262 \\
\hline & & 67.5 & 16.9 & 0.24 & 3.99 & 70 & 281 \\
\hline \multirow[t]{2}{*}{$\mathrm{P}-[\mathrm{PSS} / \mathrm{P} 2]_{8.5}$} & $29.8 \pm 0.5$ & 50.3 & 14.8 & 0.11 & 3.40 & 135 & 457 \\
\hline & & 49.4 & 13.9 & 0.11 & 3.55 & 126 & 449 \\
\hline \multirow[t]{2}{*}{$\mathrm{P}-[\mathrm{PSS} / \mathrm{P} 2]_{9.5}$} & $32.8 \pm 0.6$ & 44.6 & 13.2 & 0.09 & 3.38 & 147 & 496 \\
\hline & & 43.2 & 13.4 & 0.10 & 3.22 & 134 & 432 \\
\hline \multirow[t]{2}{*}{$\mathrm{P}$-[PSS/P3] $]_{4.5}$} & $17.5 \pm 0.3$ & 69.2 & 15.2 & 0.27 & 4.55 & 56.3 & 256 \\
\hline & & 60.2 & 14.5 & 0.26 & 4.15 & 55.8 & 232 \\
\hline \multirow[t]{2}{*}{$\mathrm{P}-[\mathrm{PSS} / \mathrm{P} 3]_{6.5}$} & $26.7 \pm 0.5$ & 43.0 & 10.7 & 0.090 & 4.02 & 119 & 478 \\
\hline & & 40.7 & 9.48 & 0.075 & 4.29 & 126 & 543 \\
\hline \multirow[t]{2}{*}{$\mathrm{P}-[\mathrm{PSS} / \mathrm{P} 3]_{7.5}$} & $29.8 \pm 0.7$ & 39.5 & 9.19 & 0.064 & 4.30 & 144 & 617 \\
\hline & & 38.2 & 8.70 & 0.053 & 4.39 & 164 & 721 \\
\hline \multirow[t]{2}{*}{$\mathrm{P}-[\mathrm{PSS} / \mathrm{P} 3]_{8.5}$} & $34.6 \pm 0.4$ & 34.2 & 8.60 & 0.055 & 3.98 & 156 & 622 \\
\hline & & 33.3 & 8.54 & 0.054 & 3.90 & 158 & 617 \\
\hline
\end{tabular}

${ }^{\text {a}}$ Permeances at ambient temperature, $10^{6} \mathrm{P} / \mathrm{l}\left(\mathrm{cm}^{3} / \mathrm{cm}^{2}-\mathrm{s}-\mathrm{cm} \mathrm{Hg}\right)$, were calculated by dividing the observed flow rate by the area of the membrane $\left(9.36 \mathrm{~cm}^{2}\right)$ and the pressure gradient (40 psi) employed, using ca. $30 \mu \mathrm{m}$ thick PTMSP (P) supports. All measurements were made at ambient temperatures. Average values were obtained from 5 - 10 independent measurements of the same sample; the error in each case was $\pm 5 \%$. Duplicate membranes are reported in all cases. ${ }^{\text {b }}$ The subscript represents the total number of bilayers. ${ }^{\mathrm{c}}$ PTMSP support without an anchor layer. 


\section{References:}

(1) Yan, X.; Janout, V.; Hsu, J. T.; Regen, S. L. J. Am. Chem. Soc., 2003, 125, 80948095 (2003).

(2) Hendel, R. A.; Nomura, E, Janout, V.; Regen, S. L. J. Am. Chem. Soc. 1997, 119, 6909-6918.

(3) Lin, C.; Chen, Q.; Yi, S.; Wang, M.; Regen, S. L. Langmuir, 2014, 30, 687-691.

(4) Hutter, J. L.; Bechhoefer, J. J. Rev. Sci. Instrum. 1993, 64, 1868-1873.

(5) Vezenov, D. V.; Noy, A.; Ashby, P. J. Adhes. Sci. Technol., 2005, 19, 313-364.

(6) Wang, M.; Janout, V.; Regen, S. L. Chem. Commun., 2013, 49, 3576-3578.

(7) Vasilev, A.; Deligeorgiev, T.; Gadjev, N.; Drexhage, K. Dyes Pigm., 2005, 66, 135-142.

(8) Futami, J.; Yamada, H.; Kyuragi, G.; Yagi, K. PCT Int, Appl., 201118731, 29 Sep2011. 